\title{
DISCURSO DE INCORPORACIÓN A LA FACULTAD DE HUMANIDADES*
}

* Echeverría de Larraín, I. (1926). Discurso de incorporación a la Facultad de Humanidades. Anales de la Universidad de Chile, 0, Pág. 181-230. doi:10.5354/0717-8883.1926.26683 


\section{DISCURSO}

DE LA

\section{Sra. Inés Echeverría de Larraín}

AL INCORPORARSE A LA FACULTAD DE HLMANIDADES 


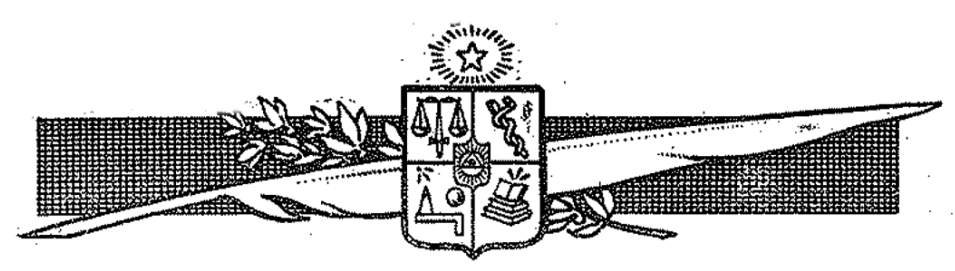

\section{DISCURSO}

DE LA

\section{Sra. INES ECHEVERRIA DE LARRAIN}

\section{AL INCORPORARSE A LA FACULTAD DE HUMANIDADES}

Cúmpleme un deber de gratitud para con esta Facultad, que me llama a compartir sus actividades.

Agradezco el honor que se me hace, a mi pais-el primero de la América Española que ha roto la tradición de permanente olvido de nuestro sexo, en los cargos públicos. I mui particularmente agradezco a esta ilustre Facultad, en nombre de la mujer chilena, la designación que ha recaido en mi. Creo sin falsa modestia, que nuestro sexo se ha necho digno de la confianza que que se le empieza a otorgar. Creo, además, que el rudo materialismo, que roe a la sociedad moderna, proviene en gran parte, de que la mujer, con su valioso bagaje espiritual, ha sido escluida de esta jornada, que en el plan divino, asignó a la pareja humana, una labor común. 
No pretendenos mujeres arebatamal hombre su predominio, en la esfera de la vida que le corresponde, pero si, necesitamos leinvindicar nuestros derechos espirituales, en la esfera superior, donde se orijina la alta inspiración que recibimos i la intuición que nos caracteriza.

Nos arrogamos, en derecho propio, lit noble ayuda i cooperación, que el hombre necesita, $i$ de que ha empobrecido miserablemente su vida, por desconocer a la mujer su rol providencial en la áspera lucha humana;

Acepto agradecida, la honrosa designación. que se ha hecho de mi persona, por la mujer chilena que represento, i no tan solo de la mujer de la aristociacia, sino especialmente de la mujer de clase media, que piensa hoi más hondo i más alto, sencillamente porque es más libre.

Agradezico también la elección que se ha hecho de mí, por la raza cuya sangre llevo, del lado en que no es posible estafar a la naturaleza, es decir, por vinculación materna.

Esta raza de caballeros del Ideal, de intelec: tuales; de estadistas i sobre todo de Poetas, me hace meritoria, por mas insignificante que sea yo personalmente, al titulo que se me otorga. Estamos en la casá de Bello, i mi présencia aqui, se acredita por eso solo. Un oscuro designio, ha permitido que los Bello, circulen ahora casi anonmos en el mundo; por haberse reproducido de preferencia, en hembras que en varones. Este caso, qua vulgarmente se imputa a mengua; pruebs en mi sentir, dentro de la sabia economía divina, 
que nuestro sexo es ahora canal adecuado, para el libre curso de las fuerzas espirituales, tan: nécesarias en el momento actual.

- La ilustre Facultad a que vengo a incorporar me, ha acertado, sin duda, en la elección del sexo i de la raza, pero ha cometido un error...

- Se equivocó de persona, pués existe en mi propia familia, la mujer eminente, representativa i completa en Dor̃a Rebeca Matte de Iñiguez.

Vengo a ocupar el sillón de Don Enrique Matha Vial, a quien no conoci: socialmente. $\hat{\imath}^{\text {Pero se }}$ conoce acaso a los hombres, en la presentación mundana, en la charla banal o siquiera en la pasion, que funde a veces los cuerpos en ausencia de las almas? Ciertamente, no: Creo que en estricta verdad, sólo conocemos a los hombres, en lo que tenemos de común con ellos, o más bien dicho, nos reconocemos a nosotros mismos, a través de las almas què se nos asemejan.

I estas afinidades son tan varias i complejas, como las almas mismas en que la naturaléza se da el lujo de diversificarse infinitamente... :

Como mujer que soi- ya que nadie ha de exijirme que me amolde a los usos masculinos-cojeré una actitud de Matta: que los hombres no se dignan tomar en consideración: la actitud íntima. Es una bellisima actitud sintética de todas las otras-actitud de verdad esencial, que muestra al ser en integridad.

Jeneralmente se admiran las actitudes públicas, 
de ciudadanos; profesionales, politicos e intelec. tuales.

Todas esas actitudes son trajes para la escena mundana. Cubren o disimulan deformidades, ocultan desviaciones, aventajan líneas o acusan bellezas. Esas maneras esteriores son disfraces escénicos. La desnudez, por decirlo asi, espiritual del hombre, se halla en si actitud intima, se revela en la reclusion del hogar, se trasparenta en el retiro de su casa, a solas con los intimos,

"Hogar feliz» significa en la psicolojía del individuo que lo ha formado, nobleza, abnegacion. sensibilidad, lealtad. Son las más bellas condiciones humanas i las que menos se cotizan en el mercado de valores sociales. Ël mundo no alcanza a distinguir aún, por una especie de maldición evanjélica, el oro del oropel.

Cuando vivia Matta, he sentido su interesante individualidad en los latidos de un corazón de mujer, i ahora que ha partido, to veo aún en el estrago con que las lágrimas quemantes han marchitado un rostro femenino: Ahi encontramos la «biografia» i el «epitafio» de Enrique Matta Vial.

I al decir "hogar». no quiero que se me tome en sentido estrecho. «Hogar» en mi sentir, equivale a intimidad, o sea, la actitud del hombre ante la mujer. Es la zona secreta en que no penetra el mundo, ni la lei; es por lo tanto el reino absoluto del corazón i de la conciencia. No alcanza hasta allá, el aplauso del público, ni la sanción penal-recinto libre, cual ningún otro, 
donde el hombre sin premio ni castigo, a solas con su conciencia, es $E l$ mismo!

¿Cuán tristes i desgarbadas suelen ser las actitudes intimas, de ciertos figurones sociales! En cambio si observamos bien, nunca hallaremos una conciencia humana verdaderamente heroica que no tenga la bella actitud de abnegación, nobleza i lealtad, ante la mujer-desvalida por la lei i herida por la naturaleza.

Podemos sentar cual la arquitectura moral de Matta, que era un hombre de corazón. I no seria yo tampoco mujer, sino asignara al «Corazón», todo el fundamento del edificio espiritual, por sobre la intelijencia i la voluntad.

El corazón, es la fuente viva de donde emana la vida del ser. Me atrevo a asegurar, que en verdad sólo sabemos lo que nos ha revelado nuestro propio corazón-misteriosa antena, que por presentimiento o adivinación, nos conduce al hondo manantial de sabiduria que no se ha escrito en libros.

Pequeño es el radio de nuestra función cerebral-simple oficina controladora de mensajes venidos de nuestro corazon. El pensamiento, es un pálido reflector, junto al foco central, originario de luz, que es nuestra sensibilidad. Sentir es conocer; ponerse en contacto directo con la vida. Pensar es darle curso oficial a un mensaje, que se visa en una oficina receptora.

Privilejio del corazón, es la reserva, Matta era reservado, tenía el pudor de sus delicados senti- 
mientos. Se entregaba solo en amistad. Sus amigos fueron escasos i, selectos. I era tan locuaz en la: intimidad, como, silencioso ante los estraños. Esta locuacidad, no escluye, sino que acentúa lo que llamaria la esencia de su Espíritu grande i elevado: el Silencio de su alma. Debo aquí esplicarme... El silencio es en las almas el prestijio misterioso que la bruma azulada da a los paisajes. Circunda, forma la majia sutil de las perspectivas:

La bruma da el color; por decirlo asi, de: la distancia; son los efluvios atmostéricos de las cum:bres, que miran los horizontes vastos i enrostran de cara al sol:

Por silencio, no entiendo tampoco. Ia abundancia, ni la escaséz de palabras. Grandes oradores son silenciosos, i seres de escasa espresión son charlatanes. Silenciosa, en mi sentir, es el alma que suprime la personalidad efímera-palabra vana de la vida esterior-i actúa dentro de los ideales a que sirve, por sobre todo cálculo mezquino; de vanidad personal, de egoismo o de ambicion humana. El alma silenciosa, es una alma cristiana por esencia, aunque no lleve el sello oficial; porque el cristianismo es la renunciación -efectiva de lo que tenemos de caduco i de limitado, como hombres, en aras de nuestro Espiritu eterno.

Matta era un silencioso. Poseĺa ese blasón, que marca a los elejidos de todo orden-en la supresion de la personalidad social; que redunda en grandeza del individuo.

Abnegacion, jenerosidad, desinterés, constancia, 
fueron los sellos con que recluyó su Espiritu en el silencio.

- El alma es silenciosa cuando logra triunfar por encima de los intereses egoístas de la personalidad humana. Matta no trabajo nunca para sí. Siempre se ocupó de nobles ideales en beneficio de sus semejantes. La modestia $i$ el absoluto desinterés, marcan la calidad del espiritu que es inalterable. I es también ésta, la sola materia que no cambia. Mejoramos o empeoramos, rejurenecemos o envejecemos, pero nuestra alma guarda su calidad como las telas guardan su materia prima. El terciopelo se estropea, pero no se convierte en tocuyo. Asi también somos nosotros. Podemos mancharnes en el camino, pero la calidad de la materia que nos constituye, se reconoce siempre. Mi antecesor poseía una excelente calidad espiritual, que probo por la constante renunciación de su personalidad, por el absoluto anónimo de su labor.

Fué un gran Silencioso. Hizo callar al hombre, ocultó su : "yo» i su alma habló en obras de eficaz ayuda a su prójimo, de servicio a su patria, dentro de la más discreta oscuridad personal.

Obro exactamente de la manera a que el Evanjelio ofrece la recompensa: «que tu mano derecha, ignore la dadiva de tu mano iaquierda.

- Esta jenerosidad, primer tributo de las almas silenciosas, to hizo culminar en el renunciamiento, ejercer la justicia i amor la verdad.

$\therefore$ «L que nienos le importaba a Enrique Matta era 
el mismo Enrique Matta», según la gráfica espresión de un amigo suyo.

tlegó hasta suprimir el «yo» en las conversaciones. La verdad, la justicia $\mathrm{i}$ el bien, constituyeron su solo afán, en perpetua fuga de esa ostentación de la Personalidad que caracteriza el egoísmo i la ambición vulgar.

Se destaca en luz espiritual la figura de Matta Vial a través del silencio que lo envuelve. Esta zona de oscuridad entre él i la vida esterior, to diseña más arriba en estraordinaria grandeza de proporción, a la vez que lo nimba de claridad.

Atravesamos una época, en que la exaltación de personalidades huecas, nos da por contraste la admiración apasionada de las escasas individualidades intensas $i$ silenciosas.

Muestra irrecusable de la justicia que amaba Matta, es su tendencia constante a los estudios históricos, en investigación de las causás orijinales, que establecen la verdad de los hechos:

El culto a la verdad, que supone el estudio del pasado, lo ha probado en los 30 volúmenes que ha publicado de documentos históricos, sobre la Independencia de. Chile. Suma enorme de oculta i paciente labor. Esfuerzo que no le reporta ningún provecho personal, ninguna gloria. Es la obra anónima que sirve a todos i que borra al autor. El artista vincula su nombre a la obra de belleza. Siente como la madre el júbilo de sú propia creación i halla enerjias para el penoso alumbramiento de la criatura suya... pero el que dedica su vida a una obra impersonal, 
necesita de una fuerza heroica, que el mundo no le pagará en moneda alguna i que sólo remunera la propia conciencia.

Matta trabajaba por amor a la verdad. Sentia ese anhelo propio de almas superiores, de rendir tributo a la armonía soberana de la vida por el silencioso acatamiento a las leyes divinas, que la historia revels, cual ningún otio ramo del saber humano, cuando se ejerce por sobre intereses partidistas, en honradez de alma.

No solo buscaba Matta en la historia la verdad interior o espiritual-alma de los hechosque viene a ser mero cuerpo que habitan ocasionalmente las ideas o las pasiones, sino que buscaba la evocación del ambiente, la vida esterior misma en que a los sucesos les tocara nacer.

Aquel culto rendido a la verdad, fué la cuna del Museo Histórico. Para Matta, la historia no era la sucesión de los acontecimientos, a que se ciñen los espiritus superficiales. Era una realidad viviente, compleja, móvil, palpitante, de que los hechos son revelaciones accidentales.

Quería el alma de las cosas pasadas, más sentida i adivinada que espresada, dentro de su envoltura material.

No ignoraba, sin duda, que los objetos, las formas plásticas, producen vibraciones, que contrenen la vida de las cosas i que afectan nuestros sentidos.

El silencio, como un divino pudor, envuelve su vida entera. Silenciosa i fecunda fué también su 
actuación como Sub-Secretario de Instrucción Pública, puesto donde adquirió en la sombra que amaba, una competencia única en su jenero, en la ciencia administrativa.

Ocupó su vida enterd en busca de documentos - ardua tarea de mártir silencioso de la Verdad, a que no vincularia su nombre, en obra alguna.

Con penoso esfuerzo llegaba a apoderarse de un documento, i en $v e z$ de utilizar el testimonio del pasado en provecho de tal o cual idea, partido o conveniencia, Matta lo publicaba íntegro.

Sin fortuna, modesto i austero en el vivir, se daba el lujo de pagar la verdad, que no le aprovecharia personalmente, al precio de sus propias comodidades $i$ de la independencia personalque siempre proporciona el dinero, además de la estimación de los necios.

Este desprecio de Matta al dinero no puedo pasarlo por alto, en la tristísima época actual, en que se rinde homenaje al dinero en forma vergonzosa, no ya al dinero actual i presente, sino al dinero futuro, como son los matrimonios fundados sobre problemáticas herencias a largos plazos.

La proverbial jenerosidad de Matta, se acusa particularmente en el uso que daba a los documentos, obtenidos a altos precios de esfuerzo también de dinero.

Jamás los ocultó. Siempre les dió circulación. Bien conocida es la mezquindad de los poseedores de documentos. Se sirven de ellos para los fines particulares que persiguen i casi siempre de 
manera incompleta, tanto vale decir: «adulterados»: - In la búsqueda de documentos, puso Matta un esfuerzo tan constante como ignorado i sin brillo. Los papeles viejos, son deságradables. Participan ya de la descomposición de la muerte. I esto unido a la dificultad de descifrarlos para un hombre de vista muy débil, como.èl, es un sam crificio casi heroico.

Me permito un paréntesis. Sólo sabemos, lo que hemos vivido. La visión material imperfecta, la miopia que no logra estrechar los contornos de los objetos, que presenta los paisajes imprecisos; todo eso "desarrolla, por justa i fatal compensación de la vida, la visión interior. El álma que tiene esmerilados los vidrios de sus ventanas, se vaelve haciä adentro; i mientras más yago es el aspectó que las cosas de afuera le presentan, más claro, nitido: i amplio es el horizonte espiritual que: se dilata ante su Espiritu. Todo aquello que las pupilas miopes de Matta, no lograron aprisionar del espectáculo circundante, el goce que le restaron a la contemplación de la naturaleza, lo adquirió por equivalencia en la visión intexior dilatada i hermosa que debió contemplar en fuerza de la mayor sensibilidad con que su alma vibrara en las atmósferas psiquicas...

Esa concentración del espíritu de Matta; esa facilidad de abstracción, son en parte, resultado de ese defecto material; que aprisiona i vuelve tímidas a las almas vulgares, $i$, que en cambio da alas a los seres superiores. Los ojos miopes de don Enrique Matta, lo desiriteresaion del presen- 
te i lo volvieron hacia atrás, al Pasado que reclamaba mayor comprénsión, para, que fuese estraida toda la esperiencia contenida...

Matta sondeó el pasado, interrogó los años pretéritos de la formación de esta: joven república i formó a nuestra juventud en el respeto de nuestras glorias.

Admiro el heroismo que necesitó para descifrar con tan débil intrumento sus ojos miopesla fotografía ya descolorida, el jeroglifico por decirlo asi, que presentan los documentos histó cos.

Su honradez i su abnegación en la entrega de los papeles viejos al público; se aquilata por comparación de lo que ocurre habitualmente. Cada colector de documentos se apodera de ellos, como de una presa, los sustrae a la comunidad a que pertenecen $i$ hace de ellos uso antojadizo. ¿Cuántos documentos han desaparecido de la Bi. blioteca Nacional? Del diario de Talavera cuyo orijinal, que no conocemos, poseyó Barros Arana completo, Matta publicó integramente el borrador fragmentario, que obturo con grandes esfuerzos. En este rasgo de Matta, se pinta su respeto a la verdad. Mientras el historiador muestra sólo lo que cuadra a sus fines, Matta hace crédito a la verdad, por sobre todas las apreciaciones, partidos $i$ opiniones, $i$ entrega al público el documento completo que posee. Sabe de instinto que sólo la Verdad plena, puede desafiar a ese inexo-

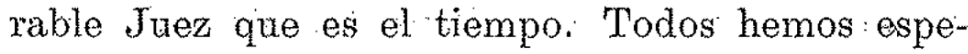
rimentado cuán difícil es' conocer la exactitud de 
un hecho, aún en el momento que ocurre, i cómo se necesita que el tiempo coloque al suceso, en la perspectiva de la distancia, que le es necesaria para mostrarse en integridad. A veces un simple dato, logra trastornar por humilde que sea, la fisonomia de una época, el carácter de un hecho histórico.

La jenerosidad de Matta se manifiesta sobre todo, en la precisa materia en qué los hombres han lucido más su mezquindad: por la sustraccion o adulteración de documentos.

Las fundaciones hechas por Matta de la Revista de Historia i Jeografía, de la Revista Nueva $i$ de la Revista Chilena, refuerran mi aserto. - Funda estas Revistas, no para sí. Para los otros.

Los diarios cojen artículos políticos o de mera actualidad social; porque el diario muere al mediodía, con la novedád que trajo. La Revista en cambio, da libre espacio a la producción literaria historica, cientifica, $\sin$ más reparo posible, que la corrección i el buen tono. Matta fundó i costeó estas revistas, en beneficio del gran público, sin distincion de ideas ni de partidos, por su culto a la verdad, a la justicia i a la belleza. $\because$ La Revista de Historia i Jeografía es la más interesante que se ha hecho en América; sus bases se copiaron en Brasil i en Arjentina. Da lugar a trabajos más estensos que en una Revista ordinaria, i también ofrece amplia cabida a los documentos históricos. Estas empresas bastarian por sí solas, para esculpir la fisonomia espiritual 
de Matta. Son el pedestal en que se levanta su noble figura moral. Cuando la Revista de Historia, con las dificultades que tales empresas supomen, dentro de la inercia española de nuestra.xa$z a, i$ de la escasez de recursos, propia de un hombre $\sin$ fortuna, se hizo lucrativa, Matta se desprendió del beneficio i lo cedio a la Sociedad misma. Rasgo es éste, de un desprendimiento raxísimo, que sólo cabe en un alma idealista, como la. suya.

Aquel hombre despreocupado de los negocios, respecto al lucro personal, así como millonario de bienes espirituales, se ocupó también: de Institu. tos Comerciales. A pesar de ser él mismo tan estraño al espíritu mercantil. Comprendió cuán necesario a nuestra raza, era ese campo de actividad i supo abrirlo a nuestro pueblo joven i mal preparado para la lucha. Estos Institutos Comerciales están fundados en todas partes para pery sonas de ambos sexos.

I aquel «poco práctico» como valgarmente se dice, en cuanto se relaçiona al egoísmo personal, ese ideólogo, aristócrata del silencio $i$ de la equi dad, supo abrir con su noble intelijencia i su desinterés, un nuevo horizonte a las actividades ciudadanas.

Sus sentimientos altamente jenerosos, se elevaron hasta el renacimiento del tesoro más indiyidual que poseemos, el único inajenable, de dax sùs propias ideas i sus estudios. \$i alguien preparaba un trabajo, Enrique Matta se apresuraba 
a suministrarle los dátos personales que él póseía,

Varios jovenes me han referido interesantes anécdutas al respecto. Domingo Santa Cruz fué a consultarlo sobre el tema de su Memoria de prueba. Le suministró 300 volúmenes i añadió sus propios comentarios.

Su jenerosidad no se colmaba con tan preciosa dádiva $i$ añadia el secreto inestimable de sus elucubraciones, de los pensamientos elaboradós en el santuario de su espiritu,

Culmina en este rasgo, lo que yo "llamaria la sublimidad de su silencio, la aristocracia de sit almá, el sello de un privilejio esclusivo de su' espiritu.

Los hombres conservan algún sentido de la honradez, respecto a documentos, pues al citarlos suelen decir como los han obtenido, pero cuando se trata de las ideas, callan, roban, adulteran; truncan. I si prestian, es con mas garantias e intexéses quio las empresas judaicas.

El pensamiento, pertenece sin duda a la mente universal, al verdadero reino de Dios, que no reconoce fronteras, a ese mundo de los Espiritus, que según Goethe, tiene libre la entrada, pero cuando tenemos acceso a ese mundo qué avaros nos volvemos con nuestros hermanos! Hacemos de tal tesoro nuestra posesión esclusiva i le pónemos nuestra cifra antes de darle circulacion!

Matta poseía ese alto sentimiento de la comanidad espiritual en el raro sentido de despojarse de sús ideas i estudios en beneficio de los demas. 
Se consideraba un simple canal anónimo, para la difusión de las ideas.

Creo que en verdad no nos pertenecen nuestros más íntimos pensamientos, ya que se forman en la callada colaboración de los espiritus afines que conviven con nosotros, en el fondo de nuestra conciencia-moradores ocultos, cuyos rostros ignoramos, pero cuyas vibraciones penetran nuestra sensibilidad i nos convencen sin palabras.

Creo en la impersonalídad de nuestras ideas más orijinales. Son mensajes que han roto la clausura aparente de nuestra alma, i que hemos recibido, no en calidad de criaturas limitadas, sino como espixitus que moran en la eternidad...

Creo en eso pero desgraciadamente no vivimos la medida exacta de nuestra fe $i$ de nuestros ideales, $i$ asi sucede, que nos es más fácil ceder nuestros bienes materiales, que la riqueza de nuestro espíritu, por más ciertos que estemos de que son particulas de la conciencia universal, concedidas en préstamo, También sabemos que esa riqueza se nos otorga tan solo en la medida de la devolución que de ellas hacemos al fondo común pero nada obsta a que insistamos egoistamente, en ponerle nuestros nombres.

Crecemos sin duda espiritualmente por el contacto que adquirimos con la conciencia espiritual del universo. Si es cierto que existimos en la vida infinita también es verdad que sólo logramos cojer en la corriente de agua, caudalosa, la cantidad que puede contener nuestro vaso. El egoísmo en este punto es superior a nuestras convic- 
ciones. Pretendemos apropiamos de este tesoro, en aras de nuestra vanidad personal. Aqui justamente es donde descuella la superioridad de Matta. Su abnegación es el eje, alrededor del cual jira su Espiritu, libre de trabas $i$ pequeñeces. Actía en profundidad, fuera de las apariencias. Labora en todas las materias, en que el personalismo cobra más fantástica proporción $i$ su desinterés toma alli mismo, maravilloso relieve.

Mientras los coleccionistas de documentos históricos, los sustraen, los ocultan, los mutilan, o los suprimen del todo, Matta los toma con esfuerzo, los paga, los guarda $i$ a su tiempo los exhibe en integridad. Funda revistas, para que escriban todos, amigos i estraños. Colabora ocultamente en trabajos que firman otros. Propoxciona datos, sin más móvil que contribuir a la difusión de la verdad o al esplendor de la belleza, en que no tocará él, gloria alguna.

Su espiritu de investigador paciente, de teriaz observador, no lo pone jamás al servicio de su nombre. iNo! Va a acrecentar silenciosamente el tesoro común, a levantar estatuas a otros idolos, pero siempre a servir sus ideales, con renunciación suma de si mismo.

Por esta razón, que me parece esencial, he clàsificado a Matta, en la más interesante de todas las categorias de hombres: las almas silenciosas!, almas elocuentisimas i activas pero que han hablado $i$ han actuado, arriba, con prescindencia absoluta de la criatura pequeña, que circula en el mun-

Avales.-Primer Trimestre,-13. 
do con un nombre. Son almas de silencio divino, porque actuaron como dioses, por medio de las causas segundas, aunque la inspiración pasa esclusivamente por ellos para alumbrar a otros...........

Me sentí algo desconcertada, cuando traté de enfocar la personalidad de Matta, tan cerrada al esterior, personalidad hosca, humana i sijilosa hasta parecerme sombria. I es que no estamos habituados al silencio. El materialismo burgués del mundo, nos oculta a los seres que no se amoldan a los usos corrientes. Tras la fachada de un palacio de ventanas cerradas, suponemos que no vive nadie. iError! Los trabajadores de verdad, se retiran al interior i se encierran en los aposentos, en donde no penetran los ruidos callejeros.

Nunca hablé con Enrique Matta. Nó me refiero a las civilidades mundanas, en que no se dicé nada. Sentí su atmósfera atrayente, i observé su manera de contemplar la naturaleza, en uno de los parajes más bellos del mundo. Quizá envidié ese don de abstracción, que ponía barreras entre él i la jente. Envolvia a Matta un halo de serenidad luminosa, una zona de silencio vivo cral aire puro, que arredraba al más intrépido perturbador vulgar, pero que no retraía a las almas de quieta i serena ensoñación.

Cuando traté de penetrarlo en su intimidad, tuve un instante de vacilación, Quise. saber cuáles fueron sus predilecciones intelectuales. ¿Dón- 
de ballo sus hermanos de espínitu? ¿Fué en el pasado? ¿Fué en el presente?

Dejé caer mi pregunta como una sonda, en la profundidad de ese océano, que es toda grande alma humana. zGustó Matta el «Juan Cristobal» de Romaín Roland? Se me contestó negativamente $\mathrm{i}$ me senti perdida. No lograría nunca ver claro en un alma, que no se había reconocido en ese grande esfuerzo de humanidad superior... Tué a causa del concepto de «patria», en que no comulgaba Matta con el autor, me contestó el amigo. Mayor turbación. Justamente ese sentimiento de la patria universal, a que pertenecemos por nuestra alma i que no compartia Matta, cultor de la verdad $i$ de la justicia (patrimonios de todas las patrics) acabó de confundirme.

Desorientada, fui a visitar el Museo Histórico, para encontrar a Matta en' aquel punto diverjente con mi espiritu, de creer que la ciudadania universal que confiere el estudio de la Historia, si no exime del amor al terruño, amplía el sentimiento de la patria común de las almas, que en ciertos casos, como entre nosotros, tan limitados por el mar i la montaña, llega a crear conflicto.

Entré al Museo i al contemplar los retratos de seres, que se han ido, Presidentes de Chile, que nos traen algunos, nuestros mejores recuerdos de la infancia o de juventud, sabios estadistas... aún al descubrir algún hermoso rostro varonil, $i$ leer el nombre de la inscripción, que lo coloca en la línea de mi propia ascendencia, mi especie 
de injénitia hostilidad al tiempo pasado i a la raza española, fué devorada por una invencible emoción...

Pasé a la sala de la guerra del Pacífico; cuyas sonoridades emotivas despertaron las cuerdas vírjenes de mi alma de niño.

Me asomé a las vitrinas, admiré las reliquias.

Descubrí en cierto rincón, una campana de la Esmeralda, sustraida al fondo de la rada de Iquique... Campana que tocó las horas tan breves como eternas de esas almas-bronce que llamó al cumplimiento del austero i monótono deber cotidiano-que vibró las horas oscuras i tristes i que también sonó las horas sublimes... I aquella campana mohosa i muda, tocó ahora para mí la cuerda sonora... Me hizo el llamado hacia atrás-siendo que amo i trabajo para el porvenir i que en cada alborada me repito: iLa vida comienầ mañana!

...Pues la campana náufraga de la nave hundida, me Hamó hacia mis héroes i mis muertos, a la raza de donde salimos a la vida... i así desterrada $\mathrm{i}$ olvidada, dijo a mi alma: «ya no llamo al servicio, no vibro en el amplio i puro aire del mar Pacífico. Vieja i olvidada, ahora toco a las almas-a las pocas que aún vagan por estas salas.... .

...Miré en torno los estandartés rotos, quernados, mustios, que ya no flamean, ni a victorias, ni a derrotas... Ví el uniforme de Prat estendido i ya con esa suprema rijidez de la muerte en sus 
pliegues inmóviles. Era el traje de Capitán que llevaba en la tarde gloriosa...

Todas las emociones tocan ahora llamada en mi alma.

Las trajedias heroicas se animan..., a traves de la humilde campana sepultada en un rincón de la sala-objeto perdido en la promiscuidad de los trofeos gloriosos...

I la campana dice entonces mui quedo a mi corazón rebelde: "Verdad es que como almas, anteriores a la vida humana $i$ posteriores a todo "tiempo, no tenérs patria, pero si la poseéis como hombres $i$ por eso contra sabias razones, una lágrima le brilla en los ojos. Así tan lejana, te he traido a tus héroes..., que no son, de los paises que te deslumbran, sino de esta tierra, en que sientes mutiladas las alas de tu. espiritu...». .

Hice entonces mi profesion de fe: «Il alma no tiene patria, pero el hombre nacido de mujer, tiene un suelo, como tïene una madres. I hagamos tambien. aquí otras confesiones.

De nacer en América Latina, habrítumos escojido ciertamente nacer aquí en esta tierra i no tampoco en la Colonia, sino en este momento, en que nace una nueva alma nacional..., el alma de la aristocracia iș!! de la aristocracia espiritual de la raza, a que sin heráldica, ni blasones, ni figuraciones históricas, pertenecen todas las criaturas, que por sobre la personalidad bre. ve, viven para los ideales i para los deberes, que impone i marca nuestro Espíritu inmortal!

Toda criatura humana, que hoi en el stupues- 
to conflicto, del Ideal con la Conveniencia (que no siempre están divorciados) prefiere el sacrificio al interés, todas esas almas de apóstoles o de mártires, poseen la única heráldica que rije lejitimamente, en la sociedad moderna.

I como esas almas, escasas ahora, serán pronto lejión, nos suprimirán el dilema, ante el cual nos hallamos detenidos, de aceptar el factor «nímero», o sea, «fuerza», por encima del factor «calidad».

Si es verdad, que ahora han nacido elementos nuevos, venidos de las clases media i baja, confesemos también que hasta ayer, sólo la clase de arriba suministró, las intelijencias i los caracteres de dominación politica i espiritual. I si yo misma me incluyo en la clase alta, es tan sólo porque tras de mí, las almas han vivido los ideales de preferencia i a veces en abierta oposición a las conveniencias.

Andrés Bello, fué tan pobre que padeció hambre en Londres, Irrisoria es, la suma que recibió por codificar todo un continente, pero asi nos legó una tan grande herencia espiritual, como exigua en pesos... Su hijo Juan Bello, recharó un gran puesto, que aseguraba el porvenir de su familia, porque bastaba a su cultivo espiritual... «No soi un gasnipiro», dijo $i$ lo tìró...

Sin esas demostraciones irrefutables de idealismo, probablemente no me hallaria yo aquí. Si habéis creido en mí, es porque ellos me presentaron a vosotros. I si me escojisteis a pesar de $\mathrm{mi}$ sexo, es porque otra mujer de mi raza, os habia firmado antes que yo sus blasones en bronce $i$ en 
mármol. I esta raza, señores, no se resigna a morir. Vive los nuevos ideales, con ardor creciente sobrevive a su nombre mismo, porque las almas de cualquier sexo que nacen con esta sangre, no dejan ni dejarán apagarse la antorcha bendita, que les légó Andrés Bello...

Si el acercamiento a la individualidad de Matta, me ha sido grato, es porque pertenece a esta aristocracia espiritual que amamos.

En el análisis de su vida, se nos presenta un hombre completo, de naturaleza ponderada i armónica, por equilibrio de sus facultades i la unidad que la condensa.

Una intelijencia clara, vasta i serena, fue siempre esclava de un corazón apasionado, pero fiel vasallo de la verdad i de la justicia.

Su alejamiento de los prestos públicos i de los honores, pudo parecer indolencia; i era tan sólo su repugnancia a lo que pudiera redundar en beneficio personal. Gustaba de darse por entero, pero ocultamente i en silencio. El ardor de sus convicciones, no alteró nunca la serenidad, ni la rectitud de sus juicios.

No actuó en política, porque los intereses meramente partidaristas, no cuadraban en la elevación de su alma ni en su injénita modestia.

Sirvió siempre a su país, con prescindencia de sí mismo, permaneciendo en la sombra i dando su precioso continjente de historiografo, de liberal acrisolado, de hombre puro, ecuánime i cordial. Los puestos públicos que se escalan a viva fuerza, 
repugnaban a su noble carácter, a la veracidad i a la justicia de su espíritu.

Su intrepidez política i su vehemencia se confiesan en su simpatía por. Carrera i por Portales.

Amaba las convicciones sinceras aunque le pareciesen estraviadas.

En su carácter de historiador i de funcionario público, nunca vaciló, ni se dejó perturbar por partidos, opiniones ni simpatías personales.

Su liberalismo fué lá perfecta concreción de su espúritu de justicia. Supo aplicar sus principios $\dot{x}$ ampliarlos en equidad, aún cuando favoreciesen a sus adversarios. A la elevación singular de su alma, se unia honda bondad i esquisita dulzura.

Su rostro tenia nobleza, concentración i serenidad. Visto en la calle parecía algo huraño, por la abstracción que produce la miopia, pero esa misma aparente hosquedad se transformaba en un grande atractivo de fuerza acumulada, que se vertía plenamente en la intimidad. Aquel hombre clausurado en la vaguedad visual de sus pupilas, cuando dejaba escapar su espíritu, se tornaba tierno, profundo, ameno i seductor. Aún aquella severidad esterior, daba mayor realce de suavidad i gracia a. su trato intimo.

El talento de Matta, consistín mucho más que en la dialéctica o en el brillo esterior de la palabra, en su penetración del fondo de las materias, en su sagacidad para descubrir lo esencial, i hacer sintesis exactas.

Su facultad de observación era honda i completa. Iba a la esencia de las cuestiones, i las 
abarcaba en su compleja totalidad, lo que añadía a su intelijencia, una prodijiosa claridad. Tenía, por eso, un conocimiento cabil de los hombres. Sus juicios eran exactos. Calculaba las posibilidades $i$ no se equirocaba en la apreciacion de los valores.

Sus amigos estimaron siempre la precisión de sus vaticinios, respecto de las personalidades que se anunciaban en el horizonte político. En los más inciertos comienzos de los hombres, Matta auguraba los éxitos o derrotas de las personalidades que asomaban en el escenario,

En la valorización de las almas iba seguramente dirijido por su corazon, más bien que por su intelijencia. En sus juicios se evidenciabd que lo más noble del ser humano, reside en el alma $i$ no en el cerebro

La balanza de Enrique Matta, como llamó su amigo Alberto Edwards, la equidad de sus juicios, es una prueba irrefutable, del ser que se guí por los sentimientos para hacer apreciam ciones.

I esta cuálidad aplicada al estudio de la historia, que amaba, han hecho de Matta la más competente autoridad en la materia. Su juició respecto de los hombres no arrancaba de la íltima impresión, sino de esa serena i constante observación, que le dió la clave del pasado.

Colector incansable de datos precisos, estaba informado cual ningún otro para emitir juicios certeros, sobre la trascendencia de los hombres i de.los hechos, cuyo desenvolvimiento fué. objeto 
de su constante estudio. Bajo este punto de vista desconfió de la «Historía filosífica», que comparó con las novelas i libros de tesis.

Su vasta recopilación de documentos, sobre la Independencia, permite reconstruir tan interesante periodo histórico de la formación chilena. Ese váliosísimo material se encuentra también diseminado en las revistas.

Dió a conocer a los eruditos, archivos riquísimos como el que formó don. Antonio Varas en muchos años. Tambien hizo traducir i reimprimir obras antiguas que tratan de nuestro país, i que arrojan mayor luz sobre el pasado.

Matta fué el inspirador de estos estudios, que nacieron con él, así como fué también un animador de voluntades, un modelador incansable de almas.

A él se debió también, la Esposición Centenaria de 1910, que dió orijen al Museo. Histórico. La prosperidad de todas sus obras, asombra en esta tierra, donde la falta de cohesión i de continuidad deben alarmarnos.

Impulso las ciencias con ardor infatigable. Trabajó en el acrecentamiento del Museo Nacional i el de Valparaíso; del Observatorio Astronómico, del Instituto Meteorolójico i Jeofísico, de lás bibliotecas, etc. Sus conocimientos sobre el derecho público teórico, hacían de Matta un maestro incomparable.

De la vida constitucional del país desde 1833, atesoró un material, que le confiere puesto único, entre los publicistas chilenos. 
Conocia la ciencia administrativa, en los más insignificantes rodajes de esa complicada máquina, como funcionario activo que fué en la Subsecretaría de Instrucciôn Pública.

Sus estudios i el inmenso caudal de lecturas, no hicieron sin embargo, de Matta, una mentalidad libresca.

Buscaba hechos que apreciar por si mismo; circunstancias que interpretar, nunca opiniones que apropiarse o que acatar.

Tomó los libros como fuente de información, nunca como directores de su espiritu libre, independiente i honrado.

Su cerebro con relación a sus lecturas fué un gabinete de química, en que su Espiritu suministraba los elementos, que su clara intelijencia transformaba dentro de la alquimia poderosa de su alma.

En armonioso equilibrio, Matta poseía todas las cualidades en que el Espiritu soberano afirma sus excelencias en la vida.

Esta individualidad eminente, tan desprovista de apariencias como rica en realidades intrinsecas, resalta i se magnífica por la constante renunciación de la personalidad, que llevó a Matta a huir siempre de la actuación pública i a rechazar honores.

«Ser i no aparecer» puido ser el lema de tan noble i fecunda vida.

No solo miraba Matta el pasado, para arrancarle el secreto del porvenir, dentro de las garantías que le daba el estudio de lós blasones de nùes- 
tra raza, sino que en el último tiempo de su vida, hizo un trabajo de palpitante actualidad. Estudió la Reforma Constitucional. Aristocrata del corazón i del intelecto debio desconfiar de las fuerzas de renovación, que nacen impetuosas i que tienden a desquiciarlo todo, pero también prestaria crédito a esas otras fuerzas ignoradas e impalpables, que nos transforman continua i silenciosamente...

Luego de subir al mando supremo el Excmo. señor Alessandri, confió a Matta el estudio de la Reforma de la Constitución.

Haré un pequeño resúmen de este trabajo, que quedó teminado, por ser de interés.

Respecto al problema doctrinario, Matta busca la solución, suprimiendo el artículo $40^{\circ}$ de la Constitución, en que se espresa que la Relijión Católica, Apostólica i Romana, es la Relijión oficial del Estado. Agrega el artículo 10, entre los derechos ciudadanos, el de libĕrtad de cultos.

Para las propiedades eclesiásticas edificadas en terrenos fiscales o municipales, según dicho proyecto, se otorgaría un título de propiedad inamovible, que no pudiera sex derogado por otra lei, sino por reforma constitucional. Supresión del Patzonato del Estado sobre la Iglesia, que asegura la libertad de dicha institución, en la elección de sus dignidades i prebendas, estensiva también a la abolición de revisar bulas, breves i rescriptos i relajamiento de votos monásticos.

La reforma de la parte politica de la Consti- 
tución, según Matta, quitaría al Senado su carácter meramente político, primando en la formación de las leyes, la roluntad de la Cámara de Diputados. El Senado se reduciría a ser Cámara moderadora i revisora. Una parte sería de representación democrática i la otra de representación funcional.

Así reflejaría mejor las fuerzas vivas de la $\mathrm{Na}$ ción.

Prórroga dé los periodos de Presidente, Senadores i Dipatados. Supresion de la Comision Conservadora i del Consejo de Estado.

Las Cámaras podrian ser también convocadas por el Senado i el Presidente tendría facultad para disolverlas. Crear incompatibilidad entre el cargo de Ministro i de Diputado. La lei de presupuestos del año anterior rejiria hasta que se despachase la nueva lei; igualmente se prorrogaría en idéntica forma la lei que fija las fuerzas de mar i tierra i la que autoriza la residencia de esas fnerzas en el lugar de las sesiones del Congreso. Disminución del «quorum» para que las sesiones se efectúen con más regularidad.

La oculta labor de Enrique Matta, su secreta colaboración en obras que no llevan su firma, los treinta volúmenes editados desde la sombra, la fundacion de sociedades que abrieron campo literario i científico a todos, sus trabajos de Sub-secretario de Instrucción, los estudios profundos con que contribuyó a la gloria de los demás, la formación de una juventud, en que incubó el amor a la patria $i$ la intelectualidad superior, su grande 
obra de animador por excelencia, me lo muestran como un celoso vijia, que desde la. alta montaña velara por nuestras instituciones, por nuestras glorias i por riestra raza... Seres que son guardianes de nuestros tesoros, almas soberanas, que por el hecho de alentar en el mundo, saturan el ambiente de espiritualidad, marcan rumbos, sostienen, elevan i dignifican a la sociedad en que viven... Mientras los fantoches actúan en el escenario, estos Espíritus, superiores, los mueven desde la sombra con hilllos invisibles, les dejan recojer el aplauso i el beneficio, i ellos se quedan serenos, modestos, desconocidos, en comunicación directa con la fuente divina, de donde todo emana... Pero, por más empeño que estos seres pongan en ocultarse, una imadiación los delata. Cerca de ellos, se encuentra la paz, se divisa el rumbo, se siente calor de vida i aliento de lucha... Inspiran confianza, dan certidumbre, producen contento... Hablan en silencio, actúan en quietud, consuelan sin palabras, animan en secreto. Junto a ellos, somos mejores, tenemos confianza en nosotros mismos, sentimos jerminar secretas enerjías i nos descubrimos cualidades ignoradas... Esas altas conciencias, están colocadas por la Providencia como anunciadoras de camino... como consejeros i jueces misteriosos de las almas. Forman en la abigarrada e inconsciente turba humana los diez justos, que pedía el Señor para salvar a la ciudad nefanda de sus iniquidades... Una de esas almas de luz $i$ de bien, pesa en las balanzas de la justicia divina, por 


\section{$-211-$}

muchedumbres de necios i corrompidos... Alumbran nuestras sombras, rescatan nuestros errores, orientan nuestros desvios...

Esta figura de Matta Vial, colocada a la sombra de todas las figuraciones políticas, al marjen de todos los serderos triunfales -alma escondida, solitarict i silenciosa, me ha sujerido por contraste el recuerdo de uno de tantos faros, que en largas travesias, por mares remotos. surjen del fondo de la tiniebla jigantesca i murmurante del océano i orientan al navegante, con su pupila de fuego. No se ve la costa. Fi cielo está cerrado. Las estrellas se apagaron.

... Una lucesilla emerje en la lejanía; surje i. se oscurece...

- En aquel sitio, una criatura humana se harecluido, lejos de sus hermanos los hombres $i$, vijúa fiel, acecha en la oscuridad de las noches, i calma la zozobra de los peregrinos...

Sentimos gratitud a esa luz piadosa, indicadora del sitio en que nos hallamos... Cuando nace la alborada, ya hemos olvidado al ignoto vijía de la víspera...

Así se me preserta Enrique Matta, ahora que he venido a ocupar su sitio en esta Corporación. Era en nuestro mundo espiritual, un faro encendido en la vasta ribera de este mar de la vida, para mostrarnos tierra...

Sus ojos miopes, se cerraron, para encender el foco interno, con que en este país joven, iba a orientar las almas, i mostrarles la peligrosa, pero bella ruta del Espíritu. 
Precisando más mi comparación, asocio a Enrique Matta en mi memoria, a una noche inolvidable...

...Fué en un viaje al país de Jesús... (No se puede decir al país de Cristo, porque Cristo es de todas las patrias). Habia cerrado la noche sobre la desolación del mar. Estaba borrada la esplendorosa pájina del cielo.

Ningún signo, ninguna ventanita estelar se mostraba en el espacio. El antro negro, se enfurecía por momento. Bramaba el mar i el barco palpitaba i jemia, como una criatura en lucha con monstruos indomables. Terror, pănico contajioso. «Está malo el mar $i$ la noche empieza» corrían voces inquietas. Lentas horas de angustia... Plegarias, alarmas... De súbito se hace perceptible apenas i luego clara i nítida, en inconmerssurable lejanía, una lucesilla débil. Viene i se va, pero pronto se afirma, se inmoviliza. Nos mira con fascinadora fijeza. Concentra en su minúsculo ojo encendido, toda la potencia del mar.

Es lo más pequeño i se enseñorea del espacio. Es un punto i vence a la inmensidad. Esta muda i clama más alto, que el estrépito del mar em. bravecido. Es pequeñísima, pero domina las sombras infinitas. No tiene consistencia i reina sobre los elementos titánicos. La luz del faro calla i atrae. Es humilde i concentra toda lit vida del infinito horizonte abierto....

Llamita miserable, es lo más ínfimo en la potencia del mar, i lo más grande, lo más exíguo de materia i lo más enorme, lo más frájil i lo 
más poderoso... Así es, señores, un grande Espiritu, en la oscuridad social. Es lo menos aparente i lo más real, lo íltimo i lo primero.

La luz emerjida así de las sombras del cielo i del mar en noche tempestuosa, trajo rumbo, consuelo i serenidad a las almas. El navio enderezó proa. I una voz comió entre los navegantes. ¡Es la isla de Malta! El faro de Malta. De este nombre, brotó como de un conjuro el ideal caballeresco, de los señores cruzados, guardianes i conquistadores de la tierra bendita-tierra de promisión espiritual!

Matta Vial se me figura así, el faro de la isla de Malta, surjido en noche negra-la época que atravesamos - $-\mathrm{i}$ dándonos con la evocación de la Isla tradicional, ya perdida en «Mare Nostrum» el ideal sagrado i puro de los hombres de antaño. Pasó aquella época, los caballeros de Malta no tienen cabida en la sociedad moderna. Guardan en Roma una melancólica villa, sobre la cima del Monte Aventino, i al caer de las tardes azuladas, cantan las fuentes antiguas las canciones seculares... Roma se dora abajo en el esplendor de esos soles, que sus muros han bebido i que ahora devuelven sus propios rayos al sol. Poniente...

No sé por qué, señores, vosotros lo adivinaréis mejor que yo, estos recuerdos han surjido en májica evocación, al sentarme en el sillón de Matta. Emerje el faro de Malta i la villa roma- 
na, ya dormida, que vibra aún en las cantarinas sonoridades de las fuentes!

Es que Matta era un hombre del pasado. Nos legó su tradición en el austero i noble escudo de las razas pretéritas, que sirven de enseña al camino nuevo!

El nos dice hoi: Vivamos la medida de nuestro Ideal. Cada existencia humana llega a la hora precisa... Importa ser uno mismo i no transijir jamás con la conciencia.

iEl aparente error de hoi, es la verdad de manana! La luz del dia que nace, trae sorpresas infinitas.

A cada hora su afán i a cada época su misión. 1Que nuestra cita espiritual de esta tarde, con este gran ciudadano, cultor del pasado i sembrador del porvenir, nos dé mayor entusiasmo, para vivir la vida, que siempre conienza mañana, enriquecida por la celosa guarda del tesoro, que cerramos ayer!

\section{Discurso contestación del miembro Académíco don Julio Vicuña Cifuentes}

Señoras, señores,

Diversas causas han retardado hasta este momento, la incorporación a la Facultad de Filosofía i Humanidades, de la señora Inés Eicheverría de Larraín, primera persona de su sexo que ha sido elejida entre nosotios para un cargo uni- 


\section{$-\cdot 215-$}

versitario. No sé yo, señores, si ante este olvidó de una tradición casi secular, se conmoverian los manes de nuestros ilustres predecesores, que no pudieron prever la entrada de Talía en el huerto de Academo; pero sí me atrevo a afirmaros, $i$ vosotros lo estáis corroborando al concurrir a este acto, que nuestra designación fué feliz, i que por sí sola justifica la alteración de una costumbre.

Podría comenzar esta lijera disertación sobre la personalidad intelectual de la señora Echeverría de Larraín, hablándoos de los títulos heredados que ella tiene para pertenecer a nuestra Universidad. Esto no estaria mal, i hasta me parece que estaría bien, dentro de nuestros hábitos dinásticos, que propenden a buscar en los abuelos la justificación de honores $i$ homenajes que, si han de valex algo, deben ser otorgados como recompensas a los méritos de quienes los reciben. Empero, no he de seguir este camino, entre otras razones, porque, para ensalzar los suyos, no necesito-recurrir a tales artificios. Prefiero vencer el miedo que me infunde su compleja personalidad, i ver modo de decir algo, mui poco, de ella misma, i aun esto con mui justificada desconfianza, porque, como ha escrito Maeterlinck; «tout ce qu'on peut dire en s'efforçant de faire le portrait intime d'un être, ne ressemble que bien imparfaitement a l'image plus précise que nos pensées traçent en notre esprit dans l'instant que nous en parlons».

Después de haber leido uno o más de sus li- 
bros, o simplemente algunos de sus artículos pexiodísticos, los que no conozcáis a la señora Echeverria de Larraín, aunque sú la época i el medio social en que se desarrolló su juventud, sentiréis acaso vivos deseos de saber cómo se realizó su formacion intelectual, cuáles fueron sus estudios, sus lecturas posteriores. Querréis àveriguar en qué fuente bebió aquella rara independencia de cririo, aquella peregrina libertad de espiritu que, sin abominar sistemáticamerte de lo pasado, por creer, o imajinar creer, que es ésta la manera de aparecer moderno, sabe aunar dichosamente lo que la tradición, como elemento étnico, tiene de bueno i duradero, con lo que el progreso evolutivo nos brinda cada dia.

Si para inquirir algo de esto, conversáis con ella, saldréis encantados de su trato, pero convencidos, al mismo tiempo, de que no habéis adelantado grar cosa. Os dirá que careció de primeros principios, que en su educación hai hondos vacios humanísticos, i que la falta de estas herramientas-es palabra suya-le ha dificultado muchas veces la ejecución de su obra. Os contará que el misticismo injénito de su alma nautrago entre fórmulas i dogmas; que la libertad de su espíritu fué cohibida con la amenaza de castigos ultra terrenos; $i$ que antes de iniciarla en el amor de la vida-de la vida, que ella ama tanto-la amedrentaron con el fantasma de la muerte.

Esto os dirá ella, convirtiendo en negaciones las afirmaciones que buscabais, $i$ vosotros, que la 
habréis escuchado con el encanto que fluye de sus palabras mismas; que antes habéis leido algún libro suyo i tropezado en él con pájinas que no podrian escribirse mejor de otra manera; vosotros; que habéis paladeado sus artículos, no solo exentos de apocados prejuicios, sino rebosan: tes de gracia i de intención, necesariamente os sentiréis tentados a contradecirla. De una parte tendréis sus propias declaraciones, sịempre iguales i terminantes; de la otra, su obra i lo que, a pesar suyo, dicen sus palabras, en contradicción con lo que están aseverando. ¿Como conciliar, entonces, estos estremos?

No es, en verdad, imposible. La señora Echerria de Larraín es una poderosa intuitiva, i ahí está el secreto de todo lo que en este punto púede parecernos estraño e incongruente. La intuición ha sido su maestra. Ella le ha dado el conocimiento de las cosas, no por arte infuso o adivinatorio, sino por percepción natural, innata en ella, tan rápida i espontánea, como penetrante i completa. Esto no puede desconocerse. En personas del talento vivo i agudo de la señora Echeverría, la intuición hace milagros. Txo que difícilmente adquieren porella los escritores de exuberante fantasía poética, es la disciplina mental, que concentra las haces, las ordena i distribuye para aprovecharlas inejor.

Aun he dudado alguna vez, sin olvidarme de los peligros o siquiera inconvenientes que acarrea, si el modo como la señora Echeverria se ha apropiado ciertos conocimientos fundamentales, 
fuera de la cátedra, no era el que más convenía. a su tomperamento. El escueto rigorismo dogmitico, en cualquier orden de ideas, no se aviene con su carácter independiente i vivaz. Tal vez por eso un dia, su espíritu se refujió en la filosofía oriental, en que Paracelso quiso iniciar "a Europa en el siglo dieciséis, i que Elena Blavastky difundio por ambos mundos a mediados del siglo diecinueve. Cierto es que la señora Echeverría no había estado inactiva hasta entonces, pero las mismas lecturas a que se entregaba, como no la satisfacian, eran incentivo para seguir buscando algo que no acababa de encontrar; algo que liberase su alma de la impedimenta de una tradición infecunda; algo, en fin, que la impulsara a la acción.

I llegó el año de gracia de 1904, como ella le llama, $i$ las hermosas i obsesionantes doctrinas derivadas de la ciencia de Sakia-Munni, fueron penetrando en su espíritu, ya preparado para recibirlas con la lectura del libro admirable de la Buena Nueva, i se hizo la luz en la noche i el orden en el caos, i al desaliento sucedió el entusiasmo, que se cristalizó en un libro. 'Habia nacido la escritora.

Ese libro vosotros le conocéis; se llama: Hacia el Oriente, recuerdos de una peregrinación a la Tierra Santa. Nada más dice su portada. No consta en ella el nombre del autor. Inés Echeverria pagaba acaso el últimó tributo a los prejuicios redivivos de otras épocas, e Iris no había llegado aún. Por lo jeneral, un libro de viajes no es sino una obra 
narrativa, en que el autor nos cuenta lo que ha visto en los diversos lugares que ha recorrido. Si el escritor es. veraz; si observa i narra bien; si tiene imajinación para animar los sucesos que refiere o los sitios que describe; si se hace leer, en fin, por la amenidad i gracia de su estilo, diremos que ha hecho un buen libro de viajes. Pero será éste un libro esterior, de mera sensación visual, porque el autor describe, pero no interpreta el paisaje; relata, pero no vive lo que se desarrolló delante de sus ojos; recuerda con la memoria, pero no evoca i reconstruye con el espiritu las escenas de que esos parajes fueron teatro en lo pasado; vivificandolo todo con el calor de la propia emoción. Por el contrario, si el autor procede de esta segunda manera, habrá hecho un libro intimo, personal, que no podrá confundirse con ningún otro; que corresponderá todavía a una situación, a un momento de su vida, porque los estados de alma raras veces se repiten.

No se trata aquí de pronunciarse sobre cuál de estos dos sistemas es mejor, dado que sea posible sistematizar la idiosincracia del escritor. Si éste tiende a la impersonalidad, hará la primera de estas obras, esencialmente narrativa i. esterior; si, al revés, sólo puede ver lo que le rodea, al través de su propio $Y O$, hará la segunda, i el libro de viajes será ante todo una suceción de estados de alma. Fl de la señora Echeverría de Larraín es de esta clase: un libro personal, mui interesante por cierto. La escritora afluente i verbosa que conoceremos más tarde, 
se muestra en él relativamente parca en las descripciones; sobria hasta cierto punto en la consideración de los detalles. La espresión de sus sensaciones mismas parece ahí más definida, más concreta que en otras obras suyas, como si la majestad de aquellos sitios no consintiera la divagación. En cambio, su estilo es menos brioso, menos rico en sonidos $i$ en colores de lo que llegará a ser después; su espontaneidad asoma, pero no se derrama; la escritora no maneja todavia todos los elementos de seducción, afectivos i verbales, de que dispone.

Otros libros suyos vinieron más tarde. Vinieron en buena hork, para revelar la multiplicidad de sus talentos. Perfiles vagos se llama uno de ellos. Es un libro inquietante. Ahí están Somya, Mizdemoiselle Marie, La Dama Fatal, el Conde de Bonny, Mademoiselle Brémond... Incomprendidos unos; infelices todos. Son perfiles vagos, que sacan la fuerza con que se nos insinúan, de su misma inquietante vaguedad. ¿Cómo ha podido trazarlos su autora? ¿̨Como ha logrado vivir la vida de aquellos seres a quienes no conoció sino un instante, para dárnoslas luego como jirones de la propia? No lo sabemos, pero al cerrar el libro, no hemos podido reprimir esta interrogación in-

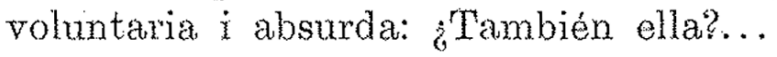

Tiema virjen es otro de estos libros. Le sirve de epigrafe la conocica trase de Amiel: «El paisaje es un estado de alma», que define perfectamente la obra. Pero aun prescindiendo en estas lineas de lo que hai ahí de interpretacion personal, (por- 
que el análisis, por somero que fuese, nos llevaria más lejos de lo que la ocásión permite), i ateniéndonos al paisaje mismo, que está admirablemente descrito, podemos decir que en este libro aparece por primera vez, que sepamos, en la literatura chilena, un esfuerzo considerable para ponernos delante de los ojos las bellezas de nuestra zona aistral, que no habian inspirado hasta entonces sino alguna que otra pájina hueca de la mas boba admiración. Hai en Tierra virjen, aquí alla esparcidos como diamantes quie se destacan en una tela recamada de pedreria, frases de una plasticidad admirable, i hai ante tedo, entusiasmo, entusiasmo sincero, de buena lei, que no ha de confundirse con el lirismo incoherente de los que agotan en las imprentas los puntos de esclam mación.

No puedo detenerme, como quisiera; en Hojas caidas i en Emociones teatrales, los otros dos volúmenes que publicó la señora Echeverria en 1910. Fr cierta manera, ambos sé enlazan, más el último que el primero, con su obra periodística. Emociones teatriles forma parte de ella, como representativo de uno de sus aspectos, mii interesante, sin duda, si bien no es de este momento entrar a considerarle en detalle, como habria que hacerlo. Hai ahí comprensión de la belleza artística, verdadero sentido crítico en ocasiones, aunque en otras, a mi juicio, se exceda en el elojio de obras mediocres, dejándose llevar de la sujestión que ejercen en su temperamento, asaz impresionable, los primores de la representación escénica. 
En 1914 publicó en Paris su novela Entre deux mondes, escrita en francés. El tema que desarrolla es una bella paradoja espiritualista que parece atrderla singularmente, pues cuatro años más tarde insistirá en ella, en una narración castellana, más breve, pero más episódica i de consecuencias menos inocentes. Se trata de un coup de foudre, de un amor que nace avasallador en el corto espacio de un viaje en ferrocarril, Él es un hombre hermoso de veinticinco años de edad; ella, una mujer encantadora que entra con paso alado en el otoño de la vida. Fil, hombre de todos los tiempos, siente el amor en la forma integral i humana que todos to sentimos; ella, mujer de escepción, sólo quiere del amor lo incorpóreo, lo que se exhala; el perfume, no la flor; la luz, no la llama. Como punto inicial de una pasion, no hai hasta aquí nada que nos maraville. Todos los ialilios: comienzan más o menos así; después; las dos corientes, la que, entrabada por el dique, se empeña en repechar la cuesta, i la que humanamente busca el declive natural del terreno, acaban por confundirse en el cance que las lleva al mar. En la novela no sucede esto: las dos corrientes se unen, pero no para descender al mar, sino para trepar a la montaña. El amor de Iseult no se humaniza; es el amor de Manfreddi el que se espiritualiza.

Si el paisaje es un estado de alma, la obra artistica también lo es; i doblemente, porque un estado de alma la produce, i muchos estados de alma la juzgan. Yo soi uno de tantos... Quiero. 
significar con esto, que en las breves palabras que voi a decir sobre la parte propiamente novelesca de este libro de la señora Echeverría, no entra para nada el crítico, que en mí no existe, sino el hombre, que juzga la psicolojía de la escritora al través de su propia psicolojía. El tipo de Manfreddi no ofrece gran interés, sea porque no lo tuviera en la concepción primitiva de la autora, o porque ésta no ahonda en él i se contenta con esbozarle. Es el de un hombre joven $\mathrm{i}$ bizarro que se ve atraido por una mujer de excelsas cualidades; que lucha con ella, poniendo en juego aquellos recursos que le sujiere, no su habilidad mundana, que todavía no la tiene, sino su propio amor, perfectamente humano; i que acaba por sometérsele, menos porque su concepto del amor haya cambiado, pues de esto no he logrado yo convencerme, que porque no puede hacer otra cosa, dominado a pesar suyo como se encuentra por los encantos de su proteica i complicadisima enemiga. Amox 0 deslumbramiento, el hecho innegable es que Manfreddi se siente fuertemente atraido por aquella mujer. Esto mismo le ocurre a Iseult; sólo que como ella impuso las normas, hai motivos para dudar de que este amor, tan rectilíneo $\mathbf{i}$ disciplinado, haya tenido en algún momento los caracteres avasalladores de una pasión. - Iseult está en la edad en que la vida es un trigal maduro que la menor chispa, incendia. En que el placer inefable del hallazgo se ve perturbado por la inquietante duda de la no correspondencia. En que no se sabe si el fuego que el alma 
nos consume, ha perdido ya la virtud de comum nicar su llama. Iseult, empero, no esperimenta ninguna de estas ansiedades, que sólo la asaltan fujitivamente en la hora postrera, cuando los aman. tes están próximos a separarse para siempre. Se sabe amada, i ella misma cree amar con una intensidad, con una exaltación que los hechos atenúan, pero que está en la lójica de aquella pasión - jla llamaremos así?-meramente espiritual. Las entrevistas i las conversaciones se suceden, sin que ocurra otra cosa que la cdaptación inconsciente de los sentimientos de Manfreddi a los de de su tiránica arsiga, i la novela concluye con la despedida de los amantes, sellada con un beso-hijo más del instinto que de la voluntad -única concesion humana hecha a ese amor otonal, que en la, vida tiene tan distinto desenlace.

Además del argumento, hai en esta novela ideas singulares que valdría la pena señalar, si hubiera espacio para esto. Quiero recordar una sola. Iseult creyente dice a Manfreddi arrelijioso: «Pratiquez... Les secrements ont une grace agissante qui vous manque». No hai duda que la ortodojia tachará este consejo; empero, difícilmente podrá negar su verdad psicolojica. El rito acaba siempre por imponer la doctrina. Por algo dijo Pascal: «Lo primero, tomar agua bendita». La obra está hermosamente escrita, i el argumento, sencillo i sin peripecias dramáticas, conducido lo mejor posible hacia un desenlace inesperado. Pero lo que de este libro quedará, no es la novela misma. A la admiración del lector 
se imponen bellezas de otro jénero, destinadas a vivir independientemente de la obra a que están incorporadas. O mucho me engar̃o, o hai ahí pájinas que reclaman un lugar en las antolojias. Las evocaciones de Roma son maravillosas. Se diría que la novela no es sino el marco destinado a contenerlas.

En 1918 publicó su postrera obra, $L a$ hora de queda. El título del volumen es el de la primera narracion, pintura fragmentariamente primorosa de los últimos e infecundos sobrevivientes de una familia aristocrática que se estrangula con el dogar de sus propios prejuicios. Fs un cuadro que puede irritar a los obstinados, divertir a los indiferentes, regocijar a los despechados i hacer pensar a los que aun tienen fuerzas i. aptitudes para reaccionar. En Bautismo de sangre, último relato de este volumen, la autora trae a nueva vida el tema del amor espiritual, que aspira a satisfacer i a satisfacerse dentro de la sola espiritualidad. Ahora el cuadro es más complicado, más dramático, más inquietante; más humano i verdadero en algunos detalles; tal vez menos verosimil en otros. Thierat es un tipo del más alto interés, cuya historia convierte en posibilidades cosas que normalmente no lo son. Pero el pobre Olivier... I aquel diabólico conde Stark... ¡Qué cosas tan peregrinas! Cierto es que en situación parecida, el filósofo Joubert, amante platónico de Paulina Beaumont, no se mostró más celoso del cabaliero de Chateaubriand.

Mas, ya es tiempo de concretar algunas ideas 
sobre la personalidad literaria de la señora Echeverria de Larraín. Desde luego, hai un punto en que estan de acuerdo los que la confiesan i los que la niegan: en reconocerle talento i dotes naturales de escritor. Porque no otra cosa que este reconocimiento significan, en los segundos,--que de los primeros no he de hablar-las siguientes frases que entresaco, sin truncarlas, de los mismos artículos en que los críticos le dirijieron sus agrias censuras. Dice uno de ellos: «Escritora por vocación, por naturaleza... Es briosa, vigorosa, de percepción rápida, de injenio sutil i agudo, de no escasa fantasia. Su frase es corta, su espresion enérjica. Su pluma corre fácil i lijera, con reflejos brillantes. Estas son las aptitudes literarias que manifestó en sus primeras producciones. ¿Como las ha cultivado? ¿Cómo las ha aprovechado?... Las ha dilapidado como caudal que nada ha costado adquirir... Tiene el alma i las aptitudes de una verdadera escritora, i alabanzas tan unánimes habrian de influir en ella con respecto al modo de juzgar sus propias obras», Otro dice: "Cuando se leen las obras de Iris, el contraste entre las cualidades que la adornan $i$ el aprovechamiento de ellas, deja en el ánimo del lector esta impresión rara: la decepción en la admiración. Abran ustedes uno cualquiera de sus libros. Desde las primeras pájinas nos sentimos en presencia de cualidades innúmeras, una sola de las cuales bastaria para hacer la fortuna de un autor. Pero junto con eso, observamos que la autora no hace más que jugar 
con semejantes cualidades... I nos sentimos apenados de ver que, invariablemente, la autora permanece inferior a sí misma».

Como ha podido verse, se le hace el cargo de no haber aprovechado mejor-de acuerdo, es claro, con el sentir del crítico-sus dotes naturales de escritor; pero no se desconocen éstas, ni siquiera se ponen en duda, que es lo que importa a nuestro propósito. J Ja parte fundamental está salvada. Iris tiene talento $i$ condiciones inmatas de escritor. Pero Iris tiene muchas otras cualidades, i, sobre todo, una, que nadie puede desconocerle, porque de su exaltación provienen sus más grandes aciertos i no pocos de sus errores: tiene la fantasía poética, una fantasía que derro. cha galas i colores, por arte espontáneo, sin rebuscamientos artificiosos. En este punto, de ningún escritor chileno, sin escluír a Pedro Balmaceda; - se puede presentar mayor copia de frases hermosas vertidas aquí i allá con jenerosidad pródiga. Si el valor de la obra se regulase por el esfuerzo gastado en realizarla, esto de producir frases bellas no seria un mérito en la señora Echeverria, sino el - ejercicio de una función fisiolójica de su intelijencia privilejiada. Hace bellas frises como la abeja produce miel; la luciérnaga luz i el ruiseñor ármonías; nada más. Pero esas frases no son bellas sólo por la música verbal ni por el brillo de las imájenes: lo son igualmente por el concepto, i es de admirar cómo, no siendo la concentración virtud habitual de esta escritora, llega en ellas muchas veces, por dichosa compenetración de la 
idea con la forma, a un grado de precisión insuperable.

Pero no es tampoco la fantasia poética la sola cualidad que distingue a esta autora. Iris es también fuertemente emotiva, Su temperamento nervioso, apasionado, vibra con todo lo que la rodea, con todo lo que su imajinación le sujiere, con todo lo que constituye su mundo interior de anhelos vagos, de hastíos imprecisos, de reacciones voluntariosas contra el ambiente, i, a las veces, contra la realidad misma de la vida. Entonces se produce una especie de desdoblamiento de su personalidad, $i$ es a un mismo tiempo, lójica $i$ paradojal, irónica i compasiva, buena i despiadada.

Esta Iris compleja, inquietante, que vibra con el momento, no está toda en sus libros. Los que no la hayan seguido sino en ellos, tendrán que aguardar, para conocerla mejor, a que publique una selección de sus artículos periodisticos. Su fuerte individualidad no le permitiria, aunque quisiera, impersonalizarse; de modo que el que conoce su obra la conoce da ella, no cristalizada en una forma más o menos definida, sino como es, sutil, espontánea, cambiante, apasionada.

Muchos reparos se le han hecho: algunos, fundados; otros, baladies o fuera de proposito. Yo, si tuviera autoridad para tanto, no le pediria sino concentración. La concentráción lleva implícitos el estudio previo del plan i su desarrollo armónico, el cual prescribe el renunciar a la insistencia, el saber detenerse a tiempo, para, no desvirtuar el efecto conseguido. En otros términos, no sacri- 
ficar el conjunto al detalle ni el matiz al color. No le armaría querella porque muchas palabras que usa tienen equivalentes más castizos en el castellano de hoi, pues sé que el vocabulario es cosa movible i mudable. Tampoco pretenderia-no faltan quienes pretendan estos desatinos-que acordara sus ideas con las mías, sus gustos con mis gustos; en una palabra, que escribiera mi obra i no la suya, pues no otra cosa significa el afán impertinente de señalar normas a los otros, sin tener en vista sino nuestras personales predilecciones o antipatías. No, nada de esto le pediría, sino que hiciera sentir el látigo a su Pegaso, que a veces se demora en el camino, tal vez porque desanda los trechos que más le agradan.

Señores, acabáis de escuchar su discurso de incorporación, en que ha hecho bellamente, justicieramente el elojio de su antecesor en esta Facultad. Esto me afecta en forma singular. Para mí, la señora Echeverría de Larraín no reemplaza sólo al compañero ilustre de Universidad, sino al amigo de toda la vida. Ya lo dije en otra ocasión: «Partió a deshora, en esa edad en que parece iniciarse un movimiento de regreso al lugar de donde salimos, en busca de los antiguos afectos; cuando los hombres que la vida separó, tienden a reunirse de nuevo: ahora, para evocar los recuerdos; ma: ñana, para arrostrar juntos las inquietudes del Más allá» (1).

(1) Revista de Historia i Jeografia. AñoXII, Tomo XบII, Núm. 47, Páj. 27. 
Serrora, estáis en vuestra casa, en el hogar que construyó vuestro grande abuelo. Nada os es estraño aquí tenéis el afecto de todos. En nuestra vieja Facultad hai anhelos de renovacion. Sabemos que el tiempo no transcurre inútilmente, i que los organismos están sometidos a las mismas leyes del. progreso metódico que rijen para los individuos que los integran. Vuestra colaboración nos será preciosa i agradable, i porque no dudábamos que contaríamos con ella, tuvimos la honra i el placer de elejiros.

Señora, estáis en vuestra casa. 